\title{
NUMERICAL SIMULATION OF THREE-DIMENSIONAL SEGMENTATION OF ELONGATED WATER BODY USING BG MODEL
}

\author{
Takaaki Uda ${ }^{1}$, Masumi Serizawa ${ }^{2}$ and Shiho Miyahara ${ }^{2}$
}

\begin{abstract}
In a slender water body with a large aspect ratio, the angle between the direction normal to the shoreline and the wave direction exceeds $45^{\circ}$, resulting in the emergence of cuspate forelands and the subdivision of a lake, because wind fetch along the principal axis becomes long. In this study, the BG model (a three-dimensional model for predicting beach changes based on Bagnold's concept) was applied to this problem. The 3-D subdivision process of a long slender water body was predicted.
\end{abstract}

Keywords: lakeshore; emergence; shoreline protrusion; BG model; 3-D beach changes; instability; self organization

\section{INTRODUCTION}

In a shallow water body such as a lagoon located near the coast, beach changes take place owing to wind waves caused by wind shear across the water body. On ordinary coasts, the angle between the direction of the incident waves and normal to the shoreline is small. In a narrow water body with a large aspect ratio, however, the wave incidence angle relative to the normal to the shoreline may exceed $45^{\circ}$ and the shoreline may become unstable owing to high-angle wave instability (Ashton et al., 2001; Ashton and Murray, 2006; Falqués et al., 2008) because the wind fetch along the principal axis of the water body is sufficiently long for waves with significant energy to be generated. Therefore, cuspate forelands that develop from both shores of a narrow water body may connect with each other, resulting in the segmentation of the water body into smaller rounded lakes (Zenkovich, 1967; Ashton et al., 2009).

Figure 1 shows the same example of the segmentation of a shallow water body facing the Chukchi

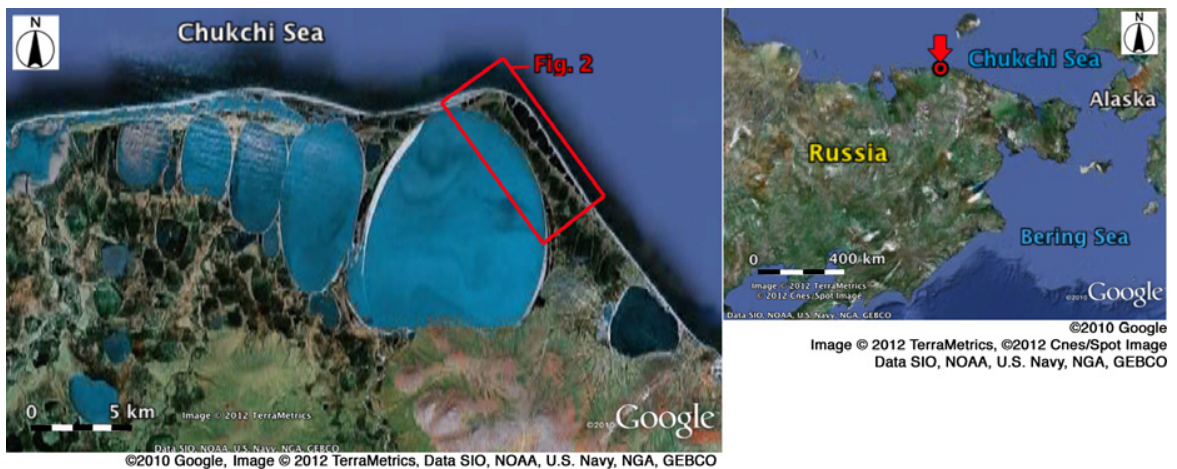

Figure 1. Example of segmentation of a shallow water body facing the Chukchi Sea in Russia.

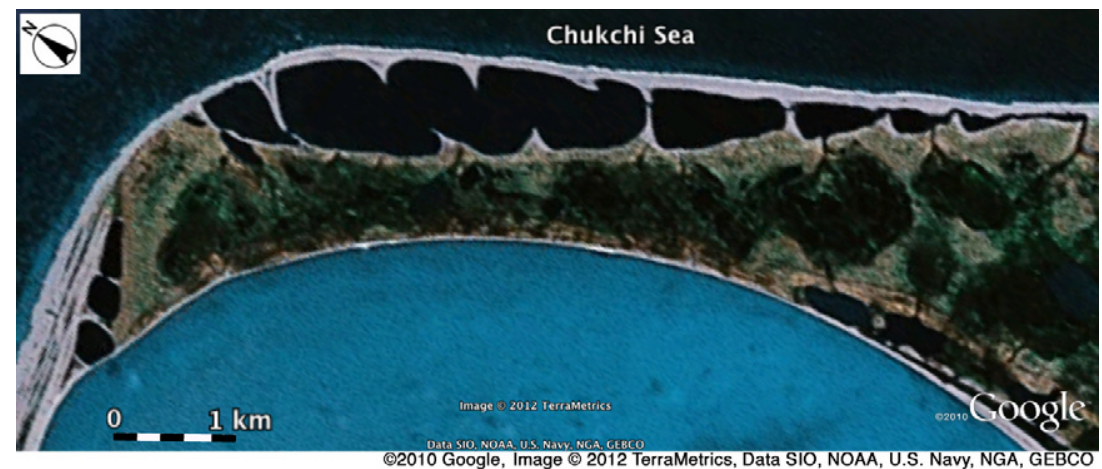

Figure 2. Expanded map of rectangular zone shown on right side of Fig. 1.

\footnotetext{
${ }^{1}$ Public Works Research Center, 1-6-4 Taito, Taito, Tokyo 110-0016, Japan

${ }^{2}$ Coastal Engineering Laboratory Co., Ltd., 1-22-301 Wakaba, Shinjuku, Tokyo 160-0011, Japan
} 
Sea in Russia as that of Ashton et al. (2009). In this case, the scales of the water bodies formed by the segmentation differ from each other and depend on the scale of the original water body. Figure 2 shows an expanded map of the rectangular zone shown on the right of Fig. 1. The segmentation of the shallow lake can be seen, and the lakeshore is at a primitive stage of development and cuspate forelands alternately develop from both shores.

Regarding these phenomena, the division and reduction of a fetch owing to the formation of a large shoreline protrusion associated with the shoreline instability under high-wave-angle conditions and the resulting change in the wave field are key factors. Ashton et al. (2001) and Ashton and Murray (2006) successfully modeled the development of shoreline irregularities into cuspate spits by considering the instability mechanism on the basis of the longshore sand transport formula. Serizawa et al. (2012) also carried out the numerical simulation of the development of shoreline irregularities using the BG model (a three-dimensional model for predicting beach changes based on Bagnold's concept) (Serizawa et al., 2006). Ashton et al. (2009) further expanded their model to be able to calculate the segmentation process of the elongated water body by introducing the calculation of wind waves from the wind fetch. In this study, the BG model was used to investigate this phenomenon, and 3-D changes during the segmentation of a shallow water body into small lakes were predicted.

\section{DEVELOPMENT OF ALTERNATE CUSPATE FORELANDS ALONG LAKESHORE}

Lake Kitaura located in the Kanto Plains, as shown in Fig. 3, is a shallow lagoon with a water area of $35.2 \mathrm{~km}^{2}$ and has a slender shape of $25 \mathrm{~km}$ length from north to south, as shown in Fig. 4. This lagoon is surrounded by the Kashima and Namekata Tablelands with an elevation as low as $40 \mathrm{~m}$ and $30 \mathrm{~m}$, respectively. Wind, therefore, can blow over the surface of this shallow water body without significant sheltering effect by the local topographies.

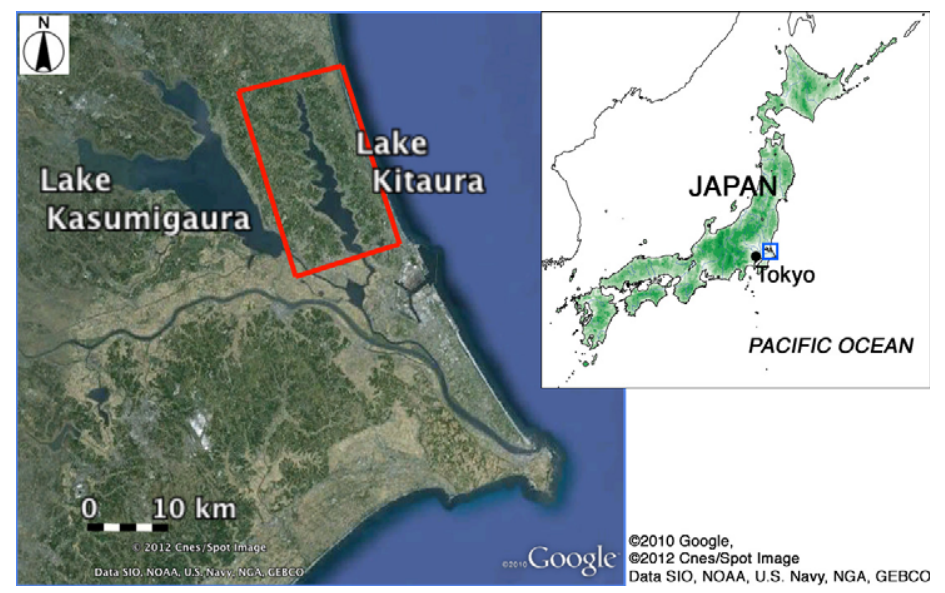

Figure 3. Location of Lake Kitaura.

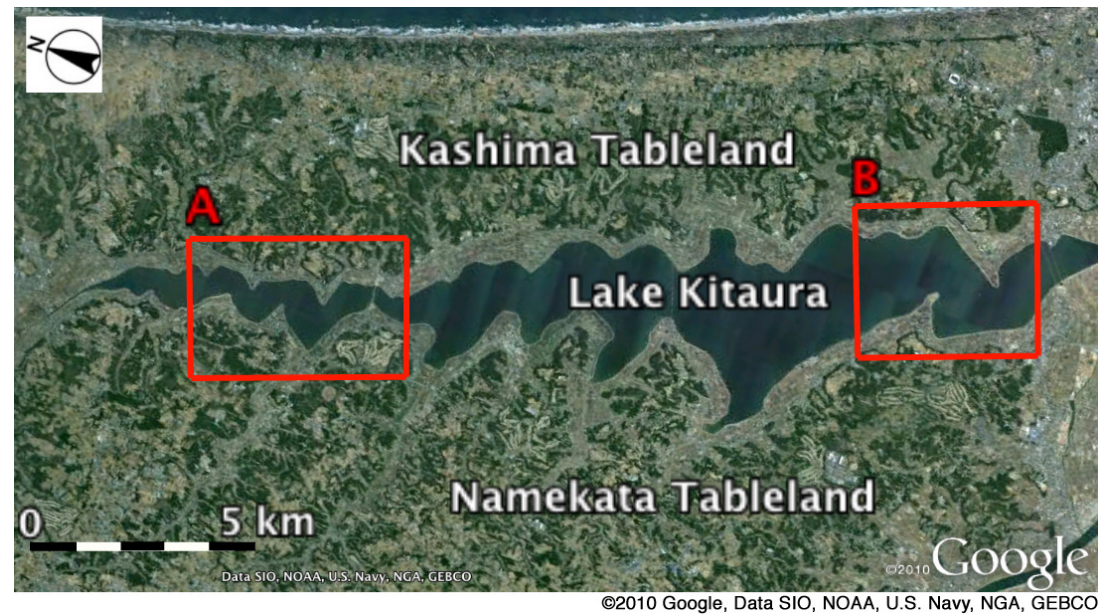

Figure 4. Formation of alternate cuspate forelands along shore of Lake Kitaura. 
Figure 5 shows the wind rose measured at the center of Lake Kasumigaura, which is located $10 \mathrm{~km}$ west of Lake Kitaura. The predominant wind directions are NNE, N and NE, which are close to the direction of the principal axis of Lake Kitaura, resulting in the generation of wind waves in the water body. In Fig. 4, many cuspate forelands alternately develop along both shores of the lake. Since the location of the cuspate forelands in the central part of the lagoon coincides with that of ridges developing toward the lagoon, it is assumed that no cuspate forelands have been formed owing to the shoreline instability, whereas cuspate forelands develop independent of the location of the ridges in the northern and southern areas of the lake.

Figure 6 shows the expanded aerial photographs of these areas. Although the scale of cuspate forelands is relatively small in area A, the cuspate forelands alternately develop, and this is very similar to the example observed in a shallow lagoon facing the Chukchi Sea in Russia, as shown in Fig. 2. On the other hand, in southern area B, the sand spits (Points Mizuhara-suo and Tsumekino-hana) developed on both shores extend alternately, which is similar to the formation of cuspate forelands in northern area A.

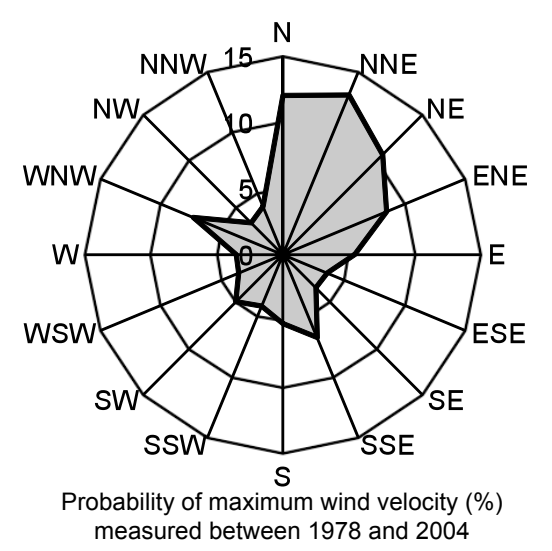

Figure 5. Wind rose at the center of Lake Kasumigaura.
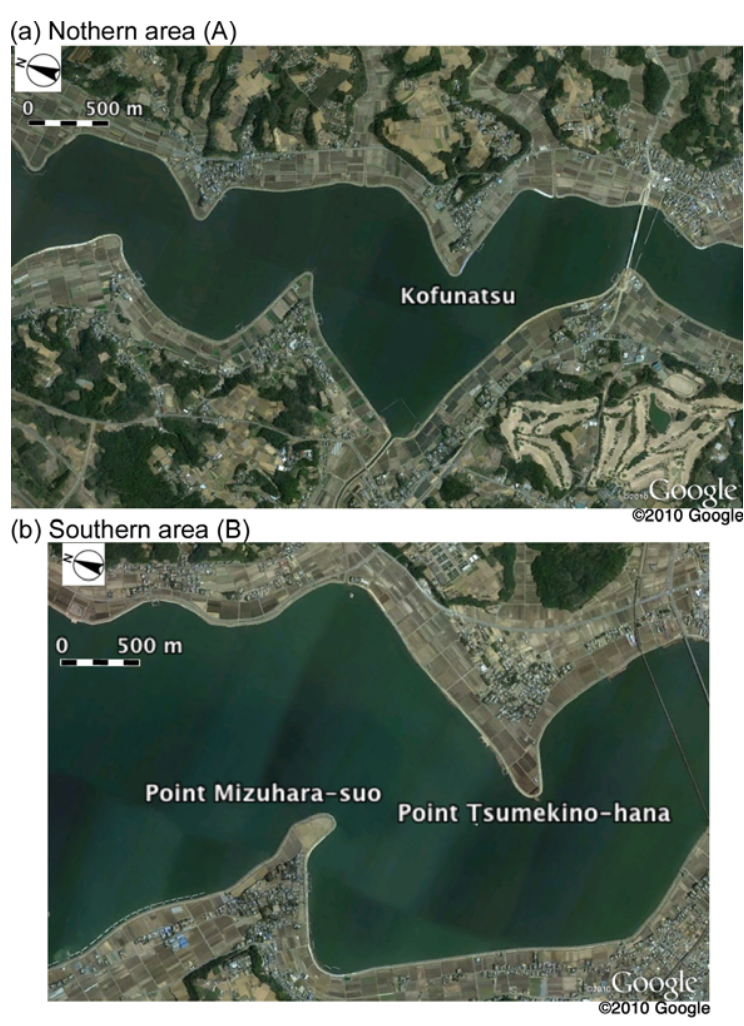

Figure 6. Expanded aerial photographs of the northern part (A) and southern part (B) of Lake Kitaura. 


\section{PREDICTIVE MODEL}

For the sand transport equation, Eq. (1), which is expressed using the wave energy at the breaking point, was used, similar to the BG model (Serizawa et al., 2006). The variables in Eq. (1) are given by Eqs. (2) - (9). In the calculation, the local beach slope measured along the wave ray was used for the beach slope in Eq. (2), as shown in Eq. (3). Prior to the calculation of beach changes, the significant wave height at a point was calculated by the S-M-B methods (Komar, 1998) given a local fetch $F$ at a point and wind velocity $U$. In this calculation, a fixed coordinate system of $(x, y)$ was adopted for the calculation of beach changes with the calculation domain of rectangular shape of ABCD, as shown in Fig. 7, whereas another coordinate system $\left(x_{w}, y_{w}\right)$ was set corresponding to the wave direction, and the wave height was calculated in the rectangular domain of $\mathrm{A}^{\prime} \mathrm{B}^{\prime} \mathrm{C}^{\prime} \mathrm{D}^{\prime}$ including the domain $\mathrm{ABCD}$.

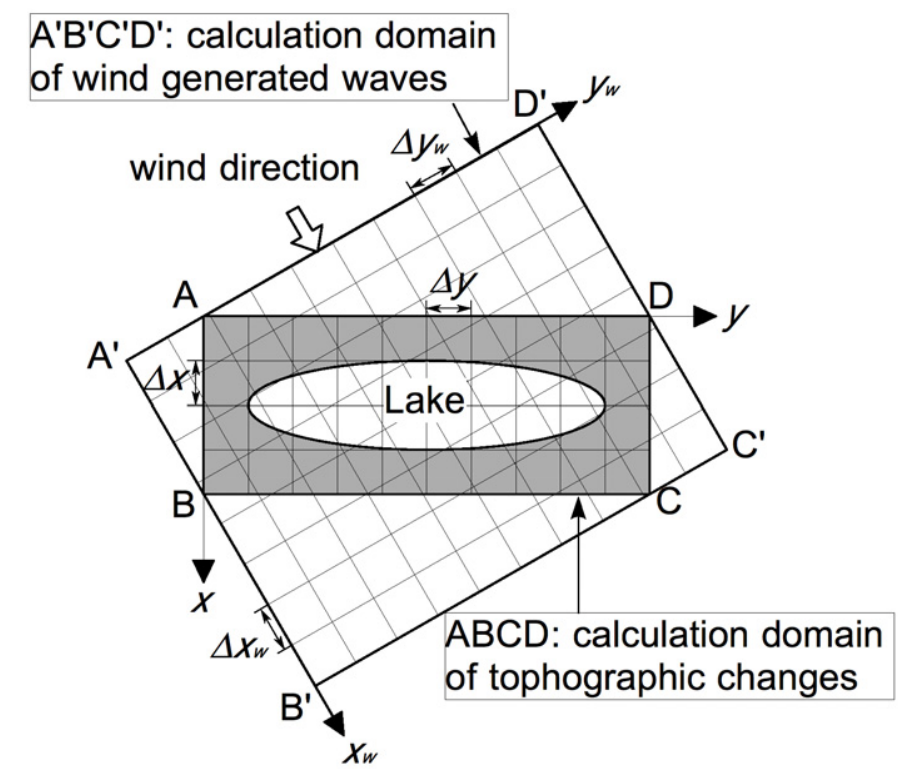

Figure 7. Definition of coordinate system.

Neglecting the wave refraction effect, waves are assumed to propagate in the same direction as the wind. The $x_{w}$-axis was subdivided by the mesh intervals of $\Delta x_{w}$. The fetch $F$ was added from upwind to downwind along the $x_{w}$-axis using Eq. (7). The increment of the wind fetch was evaluated using $\Delta x_{w}$ in a zone deeper than the depth of closure, whereas the increment was linearly reduced with the decrease in water depth in a zone shallower than the depth of closure, taking into account the wave attenuation owing to bottom friction and wave breaking. In addition, the increment of wind fetch was assumed to be 0 on the shoreline and on land (Eq. 7(b)).

When a grid point was located on land and the downslope condition of $d Z / d x_{w} \leq F$ was satisfied, the local fetch was reset as $F=0$ (Eq. 8). When the grid point was again located in the lake, $F$ was recalculated. By this procedure, the wave height becomes 0 behind the sand spit and the wavesheltering effect by the sand spit itself can be evaluated as that in the angular spreading method for irregular waves.

The significant wave height was calculated with Wilson's (1965) equation (Eq. (9)) using the wind fetch $F$ and wind velocity $U$ (Goda, 2003), and this wave height was assumed to be equal to the breaker height (Eq. 6(a)). Simultaneously, the wave power $P$ (Eq. (2)) was calculated and assigned to each grid point on the coordinates of $\left(x_{w}, y_{w}\right)$. The $P$ value at each grid point in the calculation of beach changes was interpolated from this distribution of the $P$ value.

$$
\begin{gathered}
\vec{q}=C_{0} \frac{K_{s} P}{\tan \beta_{\mathrm{c}}}\left\{\tan \beta_{c} \overrightarrow{e_{w}}-|\cos \alpha| \overrightarrow{\nabla Z}\right\} \quad\left(-h_{c} \leq Z \leq h_{R}\right) \\
P=\varepsilon(Z)\left(E C_{g}\right)_{b} \tan \beta_{w} \\
\tan \beta_{w}=d Z / d x_{w} \quad\left(\tan \beta_{w} \geq 0\right)
\end{gathered}
$$




$$
\begin{aligned}
& \int_{-h_{c}}^{h_{R}} \varepsilon(Z) d Z=1 \\
& \varepsilon(Z)=\frac{1}{h_{c}+h_{R}} \quad\left(-h_{c} \leq Z \leq h_{R}\right) \\
& \left(E C_{g}\right)_{b}=C_{1}\left(H_{b}\right)^{\frac{5}{2}} \approx C_{1}\left(H_{1 / 3}\right)^{\frac{5}{2}} \\
& C_{1}=\frac{\rho g}{k_{1}} \sqrt{g / \gamma} \quad\left(k_{1}=(4.004)^{2}, \gamma=0.8\right) \\
& F_{(i+1)}=F_{(i)}+r \Delta x_{w} \\
& r=\left\{\begin{array}{lr}
1 & \left(Z<-h_{c}\right) \\
h / h_{c}=(-Z) / h_{c} & \left(-h_{c} \leq Z \leq 0\right) \\
0 & \left(Z<-h_{c}\right)
\end{array}\right. \\
& F_{(i)}=0 \quad\left(\text { if } \quad Z \geq 0 \text { and } d Z / d x_{w} \leq 0\right) \\
& H_{1 / 3}=f(F, U) \\
& =0.30\left\{1-\left[1+0.004\left(g F / U_{2}\right)^{1 / 2}\right]^{-2}\right\}\left(U_{2} / g\right)
\end{aligned}
$$

Here, $\vec{q}=\left(q_{x}, q_{y}\right)$ is the net sand transport flux, $Z(x, y, t)$ is the seabed elevation with reference to the still water level $(Z=0), \overrightarrow{\nabla Z}=(\partial Z / \partial x, \partial Z / \partial y)$ is the seabed slope vector, $\overrightarrow{e_{w}}$ is the unit vector of wave direction, $\alpha$ is the angle between the wave direction and the direction normal to the contour line, $x_{w}$ is the coordinate along the direction of wave propagation, $\tan \beta_{w}$ is the seabed slope measured along the direction of wave propagation, $\tan \beta_{c}$ is the equilibrium slope of sand, and $K_{s}$ is the longshore and crossshore sand transport coefficient. $C_{0}$ is the coefficient transforming the immersed weight expression to the volumetric expression $\left(C_{0}=1 /\left\{\left(\rho_{s}-\rho\right) g(1-p)\right\} ; \rho\right.$ is the sea water density, $\rho_{s}$ is the specific gravity of sand, $p$ is the porosity of sand, and $g$ is the acceleration due to gravity), $h_{c}$ is the depth of closure, and $h_{R}$ is the berm height. $\varepsilon(Z)$ is the depth distribution of sand transport and is defined using Eq. (4), and in this study, a uniform distribution was employed (Eq. (5)). $\left(E C_{g}\right)_{b}$ is the wave energy flux at the breaking point, $H_{b}$ is the breaker height, $H_{1 / 3}$ is the significant wave height calculated by the S-M-B methods, and $\gamma$ is the ratio of the breaker height relative to the water depth. In addition, $k_{1}=4.004$ in Eq. (6b) is a constant in the relationship between the wave energy $E$ and the significant wave height when the probability of the wave height of irregular waves is assumed to be given by the Rayleigh distribution (Horikawa, 1988). $F$ is the local fetch, $U$ is the wind velocity, and $h$ is the water depth. The index $i$ in Eq. (7a) is the mesh number along the $x_{w}$-axis.

In the numerical simulation of beach changes, the sand transport and continuity equations $(\partial \mathrm{Z} / \partial \mathrm{t}+\nabla \cdot \vec{q}=0)$ were solved on the $x-y$ plane by the explicit finite-difference method using the staggered mesh scheme. The mesh intervals of $\Delta x_{w}$ and $\Delta y_{w}$ are the same as those of $\Delta x$ and $\Delta y$. Here, $\Delta x$ and $\Delta y$ are the mesh intervals of the coordinate system for the calculation of beach changes, and we assumed the equivalent condition of $\Delta x=\Delta y$. The calculation of waves and the $P$ value by the S-M-B methods was carried out every time step of the calculation of beach changes.

In estimating the intensity of sand transport near the berm top and at the depth of closure, the intensity of sand transport was linearly reduced to 0 near the berm height or the depth of closure to prevent sand from being deposited in the zone higher than the berm height and the beach from being eroded in the zone deeper than the depth of closure, similarly to that in the report by Serizawa et al. (2003).

\section{PHYSICAL MEANING OF SAND TRANSPORT EQUATION OF BG MODEL}

To investigate the physical meaning of Eq. (1), $\vec{q}$ in Eq. (1) is separated into the components normal and parallel to the contour line as Eq. (10). $n$ and $s$ are the local coordinates taken along the directions normal (shoreward) and parallel to the contour lines. When the inner products of the unit vector $\overrightarrow{e_{n}}$ along the $n$-axis and the unit vector $\overrightarrow{e_{s}}$ along the $s$-axis and $\vec{q}$ are taken, Eqs. (11) and (12) are derived for the cross-shore and longshore components of sand transport, $q_{n}$ and $q_{s}$, respectively. 
Furthermore, under the condition that the seabed slope is equal to the equilibrium slope $\left(\tan \beta \approx \tan \beta_{c}\right.$ ), Eq. (12) reduces to Eq. (13).

$$
\begin{gathered}
\vec{q}=q_{n} \overrightarrow{e_{n}}+q_{s} \overrightarrow{e_{s}} \\
q_{n}=\overrightarrow{e_{n}} \bullet \vec{q}=C_{0} K_{s} P|\cos \alpha|\left(\frac{\cos \alpha}{|\cos \alpha|}-\frac{\tan \beta}{\tan \beta_{\mathrm{c}}}\right) \\
q_{s}=\overrightarrow{e_{s}} \bullet \vec{q}=C_{0} K_{s} P \sin \alpha \frac{\tan \beta}{\tan \beta_{\mathrm{c}}} \\
q_{s}=C_{0} K_{s} P \sin \alpha \quad\left(\because \tan \beta \approx \tan \beta_{c}\right)
\end{gathered}
$$

In Eqs. (11) and (13), the cross-shore sand transport $q_{n}$ becomes 0 when the local seabed slope is equal to the equilibrium slope, and the longshore sand transport $q_{s}$ becomes 0 when the wave direction coincides with the direction normal to the contour lines. When a discrepancy from these conditions arises, sand transport is generated by the same stabilization mechanism as in the BG model (Serizawa et al., 2006). In the sand transport equation of the BG model proposed by Serizawa et al. (2006), $q_{n}$ becomes 0 when the seabed slope measured along the direction of the wave ray coincides with the equilibrium slope. In contrast, in this model, $q_{n}$ becomes 0 when the beach slope measured along the direction normal to the slope coincides with the equilibrium slope.

Furthermore, the coefficient of longshore sand transport is employed in the cross-shore sand transport equation of Eq. (11) because the coefficient of cross-shore sand transport is assumed to be equal to that of longshore sand transport in the general expression of the sand transport equation of the BG model (Serizawa et al., 2012).

Total longshore sand transport $Q_{s}$ is obtained by integrating the longshore sand transport $q_{s}$ in the cross-shore direction. Consider a coast with parallel contours, and assume that $\alpha$ is approximately given by the breaker angle $\alpha_{b}$. Then, $Q_{s}$ becomes Eq. (14). In addition, the power of sand transport $P$ is integrated over the range between $n=x_{c}$ and $n=x_{R}$ along the $n$-axis corresponding to the depth zone between $Z=-h_{c}$ and $Z=h_{R}$, and then it becomes equal to the wave energy flux per unit shoreline length at the breaking point as Eq. (15). By substituting Eq. (15) into Eq. (14), $Q_{s}$ is reduced to Eq. (16).

$$
\begin{aligned}
& Q_{s}=\int q_{s} d n=C_{0} K_{s} \int P \sin \alpha d n \\
& =C_{0} K_{s} \sin \alpha_{b} \int P d n \quad\left(\because \alpha \approx \alpha_{b}\right) \\
& \int_{x_{c}}^{x_{R}} P d n=\left(E C_{g}\right)_{b} \int_{x_{c}}^{x_{R}} \varepsilon(Z) \tan \beta_{w} d n \\
& =\left(E C_{g}\right)_{b} \int_{x_{c}}^{x_{R}} \varepsilon(Z) \frac{d Z}{d x_{w}} d n \\
& =\left(E C_{g}\right)_{b} \int_{-h_{c}}^{h_{R}} \varepsilon(Z) d Z \frac{d n}{d x_{w}} \\
& =\left(E C_{g}\right)_{b} \cos \alpha_{b} \quad\left(\because \frac{d n}{d x_{w}}=\cos \alpha \approx \cos \alpha_{b}\right) \\
& Q_{s}=C_{0} K_{s}\left(E C_{g}\right)_{b} \cos \alpha_{b} \sin \alpha_{b}
\end{aligned}
$$

Equation (16) is equivalent to the CERC-type formula of total longshore sand transport, which has been used for the one-line model.

Ashton et al. (2001) and Ashton and Murray (2006) successfully modeled the development of shoreline irregularities into cuspate spits caused by high-angle wave instability on the basis of the longshore sand transport formula (Eq. 16). Ashton et al. (2009) further expanded their model to be able to calculate the segmentation process of the elongated water body by introducing the calculation of wind waves. Although in Ashton et al.'s model only the longshore sand transport equation is employed as the sand transport formula, in this study, two-dimensional sand transport equations considering both cross-shore and longshore sand transport were employed, and the segmentation of a lake associated with the development of sand spits was numerically analyzed. 


\section{CALCULATION CONDITIONS}

Consider a shallow water body with a flat and solid bed, the depth of which is given by $Z=-3 \mathrm{~m}$. The lakeshore is assumed to have a berm height of $1 \mathrm{~m}$ and a uniform slope of $1 / 20$. A random noise with an amplitude of $\Delta Z=0.1 \mathrm{~m}$ was added to the depth zone between $Z=-3 \mathrm{~m}$ and $1 \mathrm{~m}$ in the initial profile. Assuming that the wind velocity is $20 \mathrm{~m} / \mathrm{s}$ and wind blows from all the directions between 0 and 360 degrees with the same probability and intensity, the wind direction at each step was randomly determined on the basis of a probability distribution function. The calculation domain was divided with a mesh size of $\Delta x=\Delta y=20 \mathrm{~m}$ and $\Delta t$ was selected to be $20 \mathrm{hr}$. The depth distribution of longshore sand transport $\varepsilon(Z)$ was assumed to be uniform over the depth, and the equilibrium slope and repose slope were $1 / 20$ and $1 / 2$, respectively. Table 1 shows the calculation conditions.

Ashton et al. (2009) showed that a slender water body is stabilized to have a circular shape when wind blows over the water body from all the directions with the same probability and strength. In this study, the same simple condition as that of Ashton et al. was assumed. The wind velocity, the main factor for determining the significant wave height, was assumed to be $20 \mathrm{~m} / \mathrm{s}$, such that the significant wave height became approximately $0.9 \mathrm{~m}$, almost equivalent to the berm height, given the wind fetch of $3.6 \mathrm{~km}$ along the principal axis of the initial rectangular water body.

\begin{tabular}{|l|l|}
\hline \multicolumn{2}{|l|}{ Table 1. Calculation conditions. } \\
\hline Wind velocity & $20 \mathrm{~m} / \mathrm{s}$ \\
\hline Berm height $h_{R}$ & $1 \mathrm{~m}$ \\
\hline Depth of closure $h_{c}$ & $3 \mathrm{~m}$ \\
\hline Equilibrium slope tan $\beta_{c}$ & $1 / 20$ \\
\hline Coefficients of sand transport & Longshore and cross-shore sand transport coefficient $K_{s}=0.2$ \\
\hline Mesh size & $\Delta x=\Delta y=20 \mathrm{~m}$ \\
\hline Time intervals & $\Delta t=20 \mathrm{hr}$ \\
\hline Duration of calculation & $6 \times 10^{5} \mathrm{hr}\left(3 \times 10^{4}\right.$ step $)$ \\
\hline Boundary conditions & $\begin{array}{l}\text { Shoreward and landward ends } q_{x}=0 \\
\text { Right and left boundaries } q_{y}=0\end{array}$ \\
\hline
\end{tabular}

\section{RESULTS OF CALCULATIONS}

Figure 8 and its bird's-eye view picture Fig. 9 show the results of the calculation of the segmentation of a narrow slender water body of $3.6 \mathrm{~km}$ length and $0.4 \mathrm{~km}$ width (aspect ratio $=9$ ) into small lakes. After 2000 steps, sand bars with irregular shapes such as cuspate spits had started to develop along the shoreline. The protrusion of the shoreline created a wave-shelter zone on the downdrift side, causing a decrease in longshore sand transport, whereas a large amount of longshore sand transport occurred at the tip of the protrusion. Thus, small-scale sand bars were absorbed into a larger sand bar. As a result, the scale of the sand bar increased after 4000 steps, and the formation of sand bars with a hound's tooth pattern continued. These predicted results and the examples observed in a water body facing the Chukchi Sea and Lake Kitaura, as shown in Figs. 2 and 6, respectively, are in good agreement.

After 8000 steps, the sand bars on both shores connected with each other, resulting in the segmentation of the elongated water body into two smaller, rounded lakes. In this study, not only the shoreline of cuspate spits as reported by Ashton et al. (2009) but also the shape of the shallow sea bottom extending offshore was successfully predicted. The segmentation continued with time and the shape of the lake became rounded. After $2 \times 10^{4} \mathrm{steps}$, the four lakes had started to become circular, and after $3 \times 10^{4}$ steps, four rounded lakes were formed.

Ashton et al. (2009) investigated the relationship between the number of lakes formed by the segmentation and the aspect ratio of the water body under the condition that wind blows from all the directions between 0 and 360 degrees with the same probability and strength, given the initial topography of the water body as a rectangular shape with changing the aspect ratio between 1 and 25 . They showed that the segmentation of the slender water body did not occur but a rounded lake was formed when the aspect ratio was smaller than 4, and that the number of lakes was approximately given by half of the aspect ratio when the aspect ratio was greater than 4. Applying these results to the present case, the number of lakes becomes 4.5 because the aspect ratio is 9 . The number of segmented lakes in the present case is 4 , and agrees with the results of Ashton et al. (2009). 
(a) 0 steps

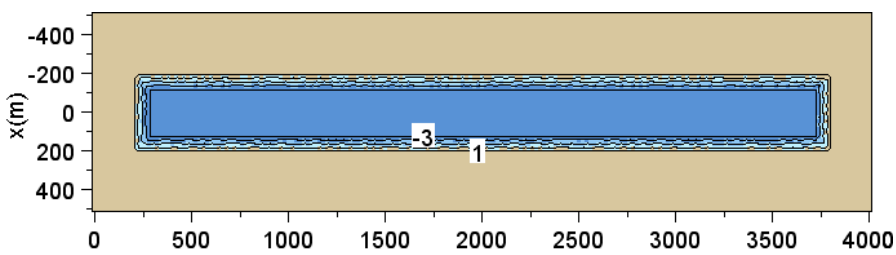

(b) $2 \times 10^{3}$ steps

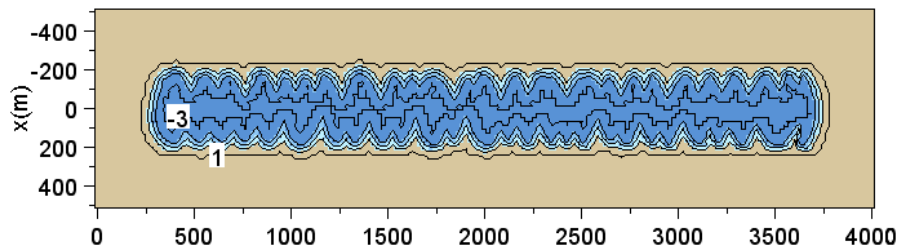

(c) $4 \times 10^{3}$ steps

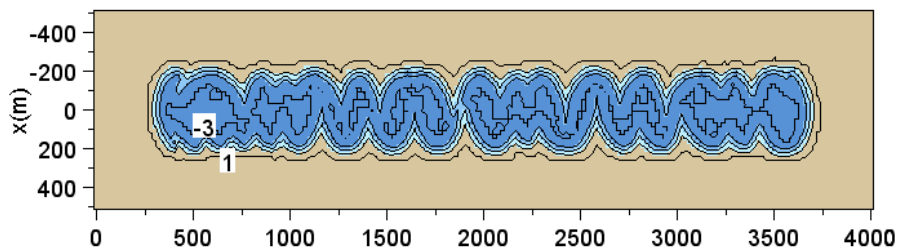

(d) $8 \times 10^{3}$ steps

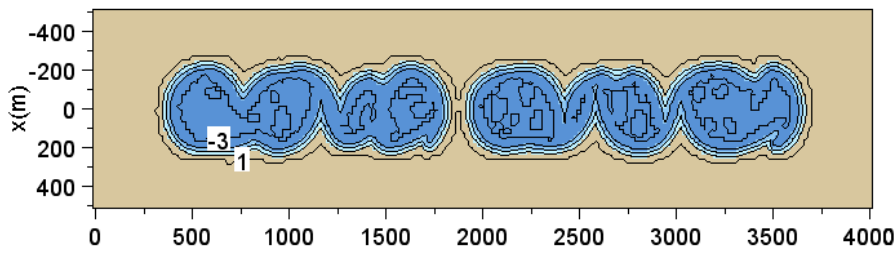

(e) $1.2 \times 10^{4}$ steps

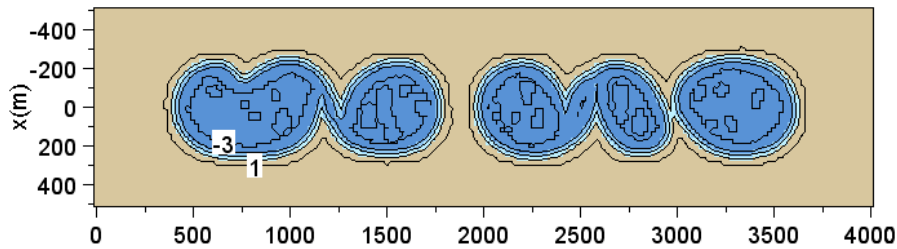

(f) $1.6 \times 10^{4}$ steps

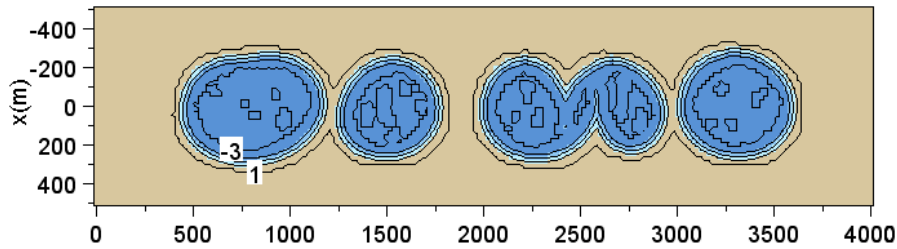

(g) $2.0 \times 10^{4}$ steps

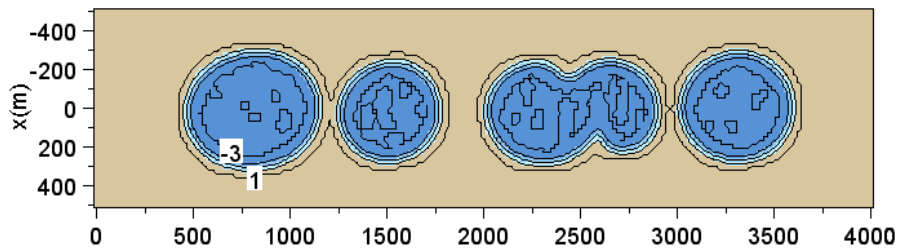

(h) $3.0 \times 10^{4}$ steps

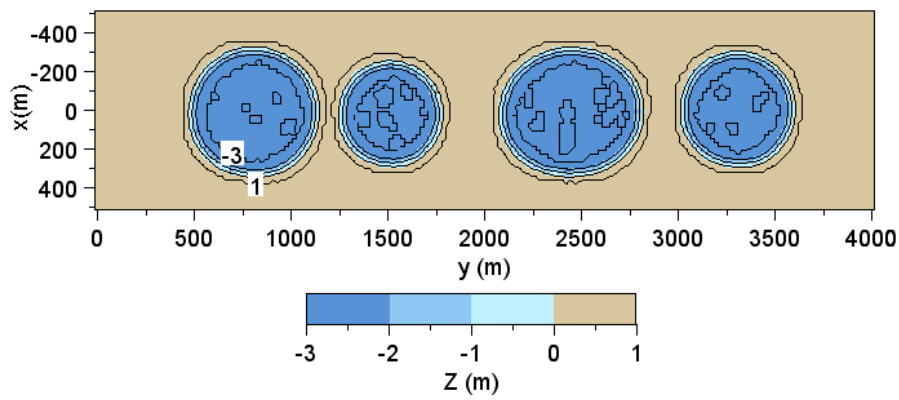

Figure 8. Results of prediction of segmentation of a slender lake of $3.6 \mathrm{~km}$ length and $0.4 \mathrm{~km}$ width (aspect ratio $=9$ ) into small lakes. 
(a) 0 steps

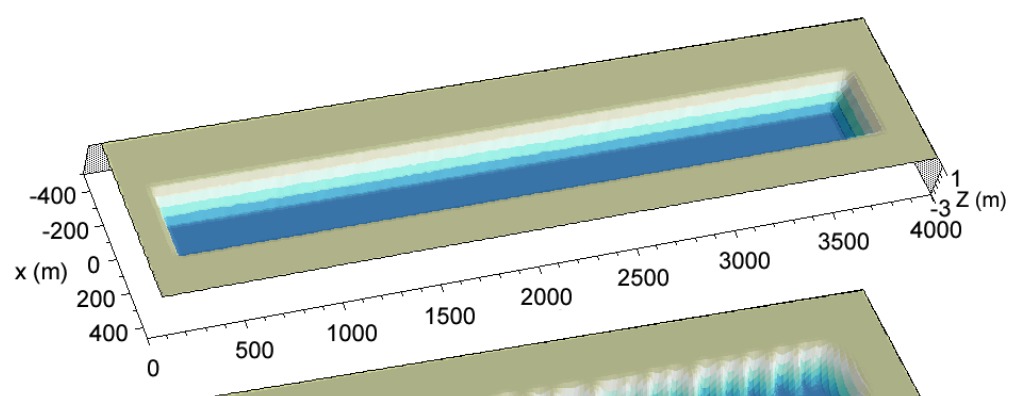

(b) $2 \times 10^{3}$ steps

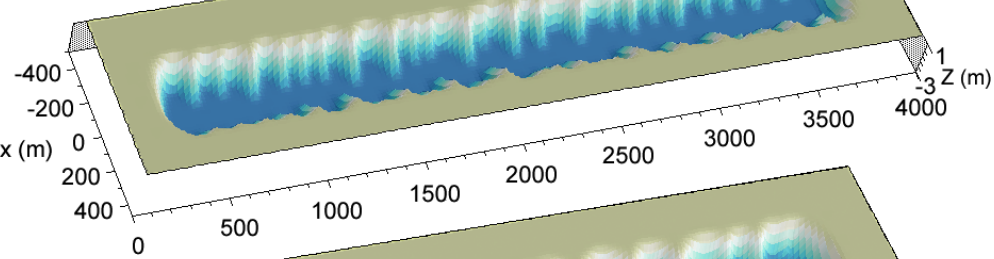

(c) $4 \times 10^{3}$ steps

(d) $8 \times 10^{3}$ steps
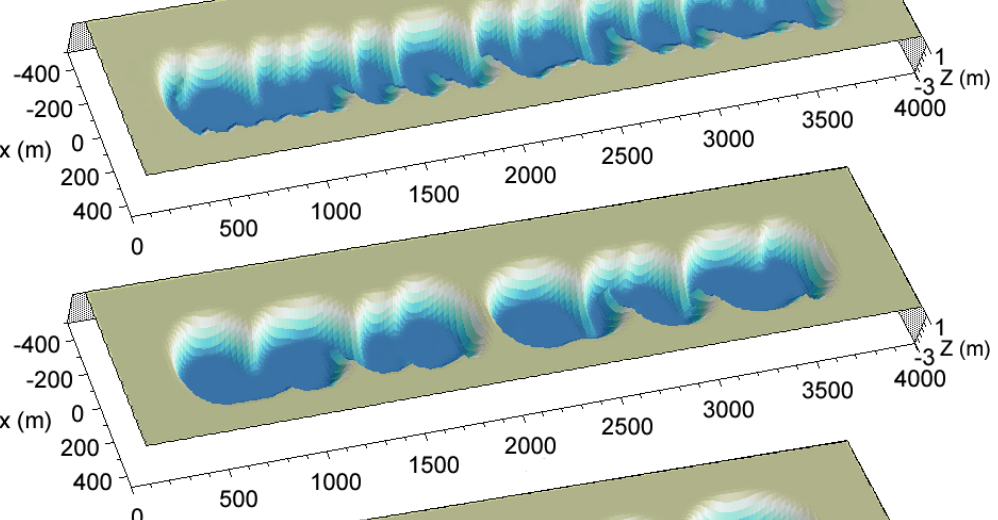

(e) $1.2 \times 10^{4}$ steps

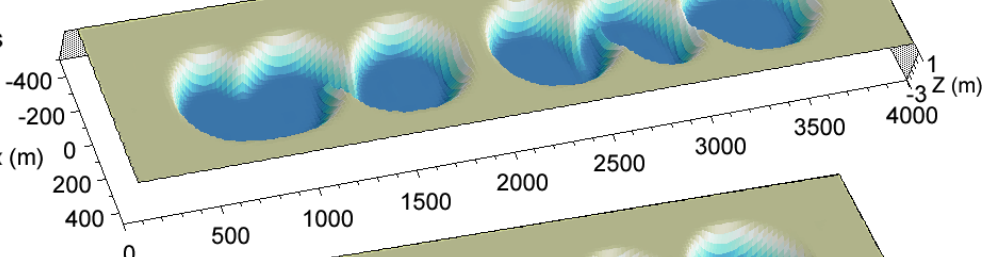

(f) $1.6 \times 10^{4}$ steps

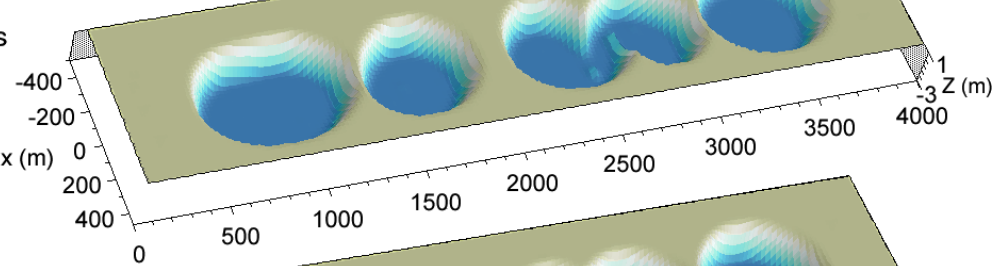

(g) $2.0 \times 10^{4}$ steps

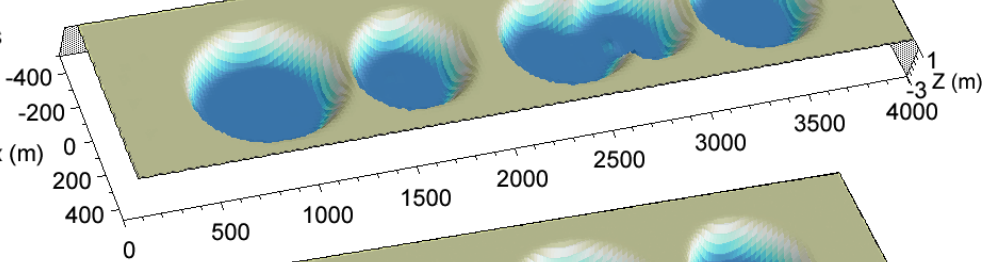

(h) $3.0 \times 10^{4}$ steps

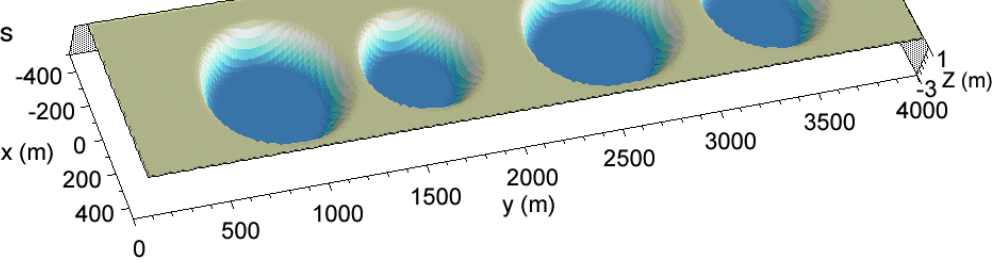

Figure 9. Bird's-eye view pictures of the segmentation of a narrow slender water body. 
Ashton et al. (2009) discussed the reasons why the segmentation did not occur when the aspect ratio was smaller than 4 by their simulations. Although the aspect ratio must be greater than 2 for the wave incidence angle to the shoreline at the center of the principal axis of the slender water body to be larger than 45 degrees, their numerical simulation showed that the minimum aspect ratio for the segmentation was larger than 4 . The segmentation of the elongated water body was about to start from both shores owing to the protrusion of the shoreline even if the aspect ratio was smaller than 4 , but the development of the shoreline protrusions ceased with the formation of the rounded lake, resulting in the protruded shoreline being eroded and becoming rounded, and finally, the segmentation did not occur. They further discussed that the phenomena were controlled by the balance between the action under a large wave incidence angle, which induces the shoreline instability, and the action under a small wave incidence angle, which causes the smoothening of the shoreline. Similar results were observed in the present study.

In the results between $1.6 \times 10^{4}$ and $3 \times 10^{4}$ steps, the lake located second from the right end started to split, but then a circular lake was formed. The segmentation of the elongated water body into four lakes was the same result as predicted by Ashton et al. (2009), but the 3-D beach changes including the formation of sand bars with a hound's tooth pattern during the segmentation process were possible to calculate.

\section{CONCLUSION}

In a slender water body with a large aspect ratio, the angle between the direction normal to the shoreline and the wave direction exceeds 45 degrees because of a long wind fetch along the principal axis, resulting in the emergence of cuspate forelands and the subdivision of a water body. In this study, the BG model (a 3-D model for predicting beach changes based on Bagnold's concept) was applied to this problem. The calculated results were compared with the ones observed in a water body facing the Chukchi Sea and Lake Kitaura. The 3-D subdivision process of a long slender water body was predicted.

\section{REFERENCES}

Ashton, A., A. B. Murray, and O. Arnault. 2001. Formation of coastline features by large-scale instabilities induced by high angle waves, Nature, Vol. 414, 296-300.

Ashton, A., and A. B. Murray. 2006. High-angle wave instability and emergent shoreline shapes: 1. Modeling of sand waves, flying spits, and capes: J. Geophys. Res., Vol. 111, F04011, doi: 10.1029/2005JF000422.

Ashton, A., A. B. Murray, R. Littlewood, D. A. Lewis, and P. Hong. 2009. Fetch limited selforganization of elongate water bodies, Geology, Vol. 37, 187-190.

Falqués, A, N. van den Berg, and D. Calvete. 2008. The role of cross-shore profile dynamics on shoreline instability due to high-angle waves, Proc. 31st ICCE, 1826-1838.

Goda, Y. 2003. Revisiting Wilson's formulas for simplified wind-wave prediction, J. Waterway, Port, Coastal and Ocean Engineering, Vol. 129, No. 2, 93-95.

Horikawa, K. ed. 1988. Nearshore Dynamics and Coastal Processes, University of Tokyo Press, Tokyo, $522 \mathrm{pp}$.

Komar, P. D., and D. L. Inman. 1970. Longshore sand transport on beaches, J. Geophys. Res., 75, 5914-5927.

Komar, P. D. 1998. Beach Processes and Sedimentation, Prentice Hall International, London, 544 pp.

Serizawa, M., T. Uda, T. San-nami, and K. Furuike. 2003. Prediction of depth changes on x-y meshes by expanding contour-line change model, Ann. J. Coastal Eng. JSCE, Vol. 50, 476-480. (in Japanese)

Serizawa, M., T. Uda, T. San-nami, and K. Furuike. 2006. Three-dimensional model for predicting beach changes based on Bagnold's concept, Proc. 30th ICCE, 3155-3167.

Serizawa, M., and T. Uda. 2011. Prediction of formation of sand spit on coast with sudden change using improved BG model, Coastal Sediments '11, 1907-1919.

Serizawa, M., T. Uda, and S. Miyahara. 2012. Prediction of development of sand spits and cuspate forelands with rhythmic shapes caused by shoreline instability using BG model, Proc. 33rd ICCE. (in press)

Wilson, B. W. 1965. Numerical prediction of ocean waves in the North Atlantic for December, 1959, Deut. Hydrogr. Zeit, Jahrgang 18, Heft 3, 114-130.

Zenkovich, V. P. 1967. Processes of Coastal Development, Interscience Publishers, New York, 751 pp. 
